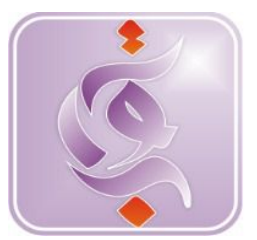

\title{
PENGELOLAAN KECEMASAN AKADEMIK SISWA MELALUI PELATIHAN REGULASI EMOSI
}

Received: 17 th June 2015; Revised: $10^{\text {th }}$ July 2015; Accepted: $28^{\text {th }}$ August 2015

\section{Irman}

STAIN Batusangkar

Email: irman.bks312551@gmail.com

\begin{abstract}
Abstrac: High academic anxiety will complicate the student to reach academic successfulness. Although in low scale, anxiety is needed by student as motivation in learning. In general, there are two factors that influence academic anxiety, namely instrinsik and ekstrinsik factor. Instrinsik factor among others jender, coping strategy, memory working. Ekstrinsik factor among others style educating of parent, social support, culture.Regulation of emotion as hereinafter factor that influence academic anxiety, having the character of instrinsik and ekstrinsik. At regulation of emotion, student instrinsik factor is triggered by stimulus that given by ekstrinsik factor. According to various literature study, found that anxiety of students' academic have negative relationship by means of signifikan with regulation emotion. This statement has meaning, excelsior of regulation emotion, progressively go down anxiety of student's academic. Based on this finding, it can be concluded that training of regulation emotion represent one of the effective intervention to lessen anxiety of students' academic.
\end{abstract}

Keyword: Management, AcademicAnxiety, and Regulation Emotion

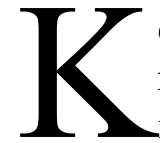

ecemasan akademik yang tinggi merupakan ancaman bagi siswa di institusi pendidikan, walaupun kecemasan akademik dalam tingkat yang sangat rendah masih diperlukan untuk memotivasi siswa dalam men-jalankan proses belajar mengajar. Matto dan Nabi (2012) menyatakan bahwa kecemasan akademik tidak selalu buruk. Tanpa rasa cemas akan membuat siswa kurang termotivasi untuk mengikuti ujian, menulis makalah dan mengerjakan pekerjaan rumah (PR).

Pada sisi lain, kecemasan akademik yang tinggi adalah hal yang sangat serius dan merupakan konsekuensi yang akan mengakibatkan yaitu: penundaan tugastugas sekolah, tidak dapat mengerjakan tugas-tugas sekolah dengan baik, gagal mengikuti proses belajar-mengajar, menarik diri dari teman sekelas, serta mempengaruhi konsentarsi dan memori.

Dampak selanjutnya dari tingkat kecemasan akademik tinggi adalah rendahnya prestasi akademik siswa. Artinya kecemasan akademik berpengaruh secara negatif pada prestasi akademik (Owens et al: 2012, Al-Qaisy: 2011, Yousefy et al: 2009, Campell et al: 2006, Cassady: 2001, Cassady and Johnson: 
2002, Yasin and Zulkifli: 2009, Y.C Singh: 2009, Vitasari et al: 2010 dan Gaziano: 2007)

Data penelitian mengungkap-kan bahwa kecemasan akademik yang dialami siswa relatif tinggi.Safitri (2011) melakukan penelitian dengan sampel berjumlah 100 orang siswa di SMAN unggul Aceh Timur.Hasil penelitian menunjukkan bahwa kecemasan akademik pada siswa SMA unggul berada dalam kategori rendah sebanyak $15 \%$, kategori sedang sebanyak $68 \%$, dan kategori tinggi sebanyak $17 \%$. Data ini mengisyaratkan bahwa kecemasan akademik siswa dominannya ditingkat sedang dan tinggi, tentu saja keadaan ini akan mengkhawatirkan bagi bebagai pihak, seperti orang tua, sekolah dan siswa itu sendiri.

Penelitian Wahyuni (2005) yang dilakukan di SMP 21 Kota Malang mengungkapkan bahwa siswa yang tidak bisa mengelola emosi dengan baik mengakibatkan perasaan marah $(64,28 \%)$, cemas $(53,3 \%)$, dan sedih 48,34\%. Selanjutnya $\quad 97,37 \quad \% \quad$ responden menyatakan bahwa pelatihan pengendalian emosi perlu dilakukan. Maka perlu kiranya kecemasan dan depresi remaja dikurangi, agar tidak menganggu proses belajar dan kegiatan sehari-hari.

Pengontrolan emosi siswa memang perlu ditingkatkan. Fransiska (2010) meneliti tentang stabilitas emosi siswa SMK 8 Bandung, dalam penelitian tersebut terungkap bahwa $89,7 \%$ stabilitas emosi siswa dalam kategori sedang. Selanjutnya pengelolaan emosi siswa dalam kisaran $63,39 \%$. Tentu saja dengan angka persentase tersebut belum memadai bagi siswa untuk menghadapi tantangan zaman yang semakin berat.

Data-data tentang kecemasan akademik siswa di atas mengisyaratkan bahwa tingkat kecemasan akademik siswa di Indonesia masih tinggi, maka perlu dicarikan suatu intervensi yang bisa mengurangi kecemasan akademik siswa
tersebut.Salah satu intervensi yang bisa diberikan adalah melalui pelatihan regulasi emosi.

Kesek (2010) dalam pene-litiannya mengungkapkan bahwa pengembangan regulasi emosi secara langsung dan tidak langsung mengurangi tekanan psikologis pada anak (sampel penelitian anak-anak usia 5-12 tahun). Hampir bersamaan dengan penelitian kesek, Cisler et al (2010) menyatakan bahwa regulasi emosi akan mengurangi kecemasan.Izard et al (2011) mengungkapkan bahwa regulasi emosi memberikan berbagai manfaat dalam kehidupan manusia.Salah satu manfaatnya adalah memperkecil tekanan emosional.Melalui penelitiannya Kallay et al (2009) mengungkapkan bahwa regulasi emosi dapat meningkatkan kualitas mental.Hal ini menunjukkan bahwa siswa perlu diberikan pelatihan regulasi emosi.Agar kecemasan akademiknya menurun.

Berdasarkan pentingnya pengelolaan kecemasan akademik siswa dan kemungkinan dapat diintervensi melalui pelatihan regulasi emosi, maka peneliti bermaksud mendalaminya melalui kajian literatur sebagai jawaban keefektifan regulasi emosi dalam mengelola kecemasan akademik siswa.

\section{A. Kecemasan Akademik}

1. Pengertian KecemasanAkademik

Kata-kata kecemasan akademik sudah biasa digunakan oleh praktisi pendidikan, dan ini merupakan kendala yang ingin dicarikan solusinya.Kecemasan akademik diartikan beragam oleh para ahli.Mato \& Nabi (2012) menyatakan bahwa kecerdasan akademik adalah perasaan mental yang berat atau distress terhadap situasi sekolah karena adanya persepsi negatif.Kecemasan akademik yang dialami oleh siswa di sekolah dapat dipantau melalui gejala-gejala tertentu.Cassady \& Johnson (2002) menyatakan bahwa kecemasan akademik 
dapat dilihat dari tiga gejala, yaitu cognitive symtoms, emotional symtom dan bodily symtoms.

Cognitive symtom adalah gejalagejala kecemasan akademik yang terdeteksi melalui cara-cara berfikir siswa. Cassady (2001) menyatakan bahwa ciriciri kognitif dari kecemasan akademik adalah: (a) cemas atau takut gagal, (b) tidak relevan dalam berfikir, dan (c) keterbatasan dalam berfikir.

Emotional symtom adalah gejalagejala psikologikal dalam menilai situasi. Gejala-gejala tersebut dapat terdeteksi melalui: (a) pusing, (b) muak, dan (c) merasa panik (cassady \& Johnson, 2002).

Bodily symtom adalah gejalagejala pisiologikal akibat dari respon proses emosi. Di sekolah siswa sering menampakkan gejala pisiologikal, seperti ketika marah pada teman sekelas mata terbelalak, nafas tersengal-sengal, otototot wajah kelihatan tegang dan intonasi suara jadi meninggi.

Ketiga gejala kecemasan di atas jika terjadi pada siswa, akan menganggu dalam proses belajar mengajar dan pada aktivitas siswa sehari-hari. Untuk mengatasi gejala ini, maka diperlukan bantuan dari guru, konselor sekolah ataupun psikolog.

\section{Faktor-faktor yang Mempengaruhi}

Kecemasan Akademik

Kecemasan akademik yang dialami oleh siswa di sekolah biasanya dibagi atas tiga tingkatan, yaitu low, avarage, and high, yaitu rendah, sedang dan tinggi (Cassady \& Johnson, 2002). Kecemasan akademik sedang dan tinggi ini merupakan kendala bagi siswa untuk mencapai prestasi akdemik.

Banyak faktor yang mempengaruhi tingkat kecemasan akademik siswa, salah satu faktor yang mempengaruhi adalah jender. Berbagai hasil penelitian mengungkapkan bahwa ada perbedaan tingkatan antara kecemasan akademik siswa laki-laki dan siswa perempuan (Al-Qaisy: 2011, Smith\& Renk: 2007, Mato \& Nabi: 2002, Corsini: 2009, Bhansali \& Trivedi: 2008, Yasin \& Zulkifli: 2009, dan Kesek: 2010).

Cara kerja memori merupakan hal yang dapat mempengaruhi kecemasan , Owen et al (2012) mengungkapkan bahwa working memory merupakan faktor penting yang dapat mempengaruhi kecemasan. Hal ini berkaitan dengan cara kerja otak. Regulasi emosi adalah hal lain yang mempengaruhi tingkat kecemasan siswa (Garnefski \& Kraalj, 2007).

Faktor selanjutnya yang mempengaruhi tingkat kecemasan akademik siswa dalah parenting style, yaitu gaya pengasuhan orang tua dan attachman (Smith \& Renk: 2007, dan Benoit et al: 2010). Dukungan sosial dan coping strategy merupakan faktor lain yang mempengaruhi tingkat kecemasan akademik siswa (Corsini, 2009). Budaya merupakan faktor yang tidak dapat diabaikan dalam mempengaruhi tingkat kecemasan akademik siswa, Dedeyn (2008) mengungkapkan dalam hasil penelitiannya bahwa di Amerika terdapat perbedaan kecemasan dari kultur yang berbeda.

Beberapa uraian di atas menjelaskan bahwa faktor-faktor yang mempengaruhi kecemasan akademik siswa adalah Jender, Working memory, regualsi emosi, parenting, coping strategy, dukungan sosial dan kultur.

\section{B. Regulasi Emosi}

1. Pengertian Emosi

Sebelum membahas pengertian regulasi emosi, alangkah baiknya terlebih dahulu dibahas pengertian emosi.Frieda (1993) menjelaskan bahwa emosi adalah perasaan intens yang ditujukan kepada seseorang atau sesuatu.Emosi adalah reaksi terhadap seseorang atau kejadian. Emosi dapat ditunjukkan ketika merasa senang mengenai sesuatu, marah kepada seseorang, ataupun takut terhadap sesuatu Kata "emosi" diturunkan dari kata bahasa 
Perancis, émotion, dari émouvoir, 'kegembiraan' dari bahasa Latinemovere, yang berarti bergerak ke luar.

Oxford dictionaries ( 2012) mengartikan emosi sebagai perasaan yang kuat yang diperoleh dari satu keadaan, suasana hati, atau hubungan dengan orang lain. Saarni et al (Santrock, 2007) mende-finisikan emosi sebagai perasaan atau afeksi yang timbul ketika seseorang sedang berada dalam suatu keadaan atau suatu interaksi yang dianggap penting.

Berdasarkan berbagai pendapat ahli di atas dapat disimpulkan bahwa pengertian emosi yaitu reaksi dalam bentuk perasaan yang kuat dan fikiran yang jelas, meliputi wilayah psikologis dan biologis dan mendorong orang berperilaku dalam keadaan atau interaksi tertentu.

\section{Pengertian Regulasi Emosi}

$$
\text { Emosi akan mendatangkan }
$$

manfaat dan kegembiraan dalam kehidupan manusia, jika manusia dapat mengaturnya sebaik mungkin. Pengaturan emosi disebut juga dengan regulasi emosi.Regulasi emosi menurut Gross and Thomson (2007) adalah suatu kemampuan untuk mengendalikan emosi yang dialami dan mengekspresikan emosi tersebut secara baik, yaitu bereaksi sesuai dengan sistim sosial yang berlaku. Selanjutnya Regulasi emosi diartikan Thompson (1994) sebagai serangkaian proses ekstrinsik dan instrinsik yang bertanggungjawab untuk memodifikasi reaksi emosional.

Seiring dengan pendapat Thompson di atas,Baumesiter et al (2008) menyatakan bahwa regulasi emosi adalah suatu kemampuan untuk menonjolkan suasana hati yang positif, dan mengurangi suasana hati yang negatif, atau mengontrol mood alami. Selanjutnya Lopes et al (2005) menyatakan bahwa regulasi emosi adalah kemampuan memahami emosi sendiri dan emosi orang lain dalam berbagai situasi dan membutuhkan keterampilan intrapersonal dan interpersonal dalam mengekspresikanya.

Pengertian pengontrolan emosi menurut Moorman (2011) the ability to logically analyze the current hand while eliminating negative feelings from past hands. Emosional kontrol diartikan kemampuan analisa logika untuk mengeliminasi perasaan negatif sebelum perasaan tersebut terjadi.

Senada dengan pendapat Moorman di atas, pernyataan Marimus (2012) emotional control Instead of repressing and ignoring your unwanted emotions, or trying to rationalize them away, step outside of yourself and analyze them by trying to find out what caused them, what was the first cause. Pengelolaan emosi adalah menekan dan mengabaikan emosi yang tak diinginkan, atau mencoba untuk berpandangan rasional, dan mencari jalan keluar dari penyebab emosi tersebut.Selanjutnya pendapat Stein (2009) manage emotion is (1) Indentify your feeling, (2) Determine what belief, cause negative emotions, and (3) stop self descructive behaviors.

Berbagai pendapat di atas dapat disimpulkan bahwa yang dimaksud dengan regulasi emosi adalah suatu kemampuan individu yang melibatkan proses instrinsik dan ekstrinsik untuk dapat memahami dan mengendalikan emosi yang dialami, serta mengekspresikan emosi tersebut secara baik sesuai dengan sistim sosial yang berlaku.

3. Faktor-faktor yang Mempengaruhi Regulasi Emosi

Banyak faktor yang mempengaruhi regulasi emosi. Faktoryang mempengaruhi regulasi emosi tersebut adalah regious coping strategis, dan attachment belief (Corsini, 2009). Faktor selanjutnya yang berpengaruh yaitu, faktor intrapersonal dan interpersonal (Kappas: 2011, Tamir: 
2011, Campos et al: 2011, \& Stifter: 2002). Penelitian selanjutnya yang mengungkapkan bahwa faktor yang mempengaruhi regulasi emosi yaitu fungsi syaraf, kognitif, dan tingkah laku (Izard et al, 2011).Benoit\&Bouthiller (2010) menyatakan bahwa attachment merupakan faktor yang mempengaruhi regulasi emosi.

Faktor selanjutnya yang mempengaruhi regulasi emosi adalah jender dan depresi, hal ini sesuai dengan hasil penelitian yang dilakukan oleh Sumida (2010).Faktor budaya juga turut mempengaruhi regulasi emosi. Lu et al (2012) mengungkapkan hasil penelitiannya bahwa etnis Tibet lebih tinggi regulasi emosinya dibanding etnis monggolia, hui dan Huighur.

Schmidt et al (2010) mengungkapkan bahwa penilaian diri merupakan salah satu faktor yang ikut mempengaruhi regulasi emosi.Selain itu, kemampuan individu juga merupakan faktor yang mempengaruhi regulasi emosi. Fay (2011) mengungkapkan dalam hasil penelitiannya bahwa regulasi emosi dipengaruhi oleh temperamen, pola asuh yang negatif dan tingkah laku internal.

Berdasarkan uraian di atas, dapat disimpulkan bahwa secara garis besar ada dua faktor yang mempengaruhiregulasi emosi yaitu; intrapersonal yang berkaitan dengan fungsi syaraf, kognitif, attachment belief, depresi dan penilaian diri serta temperamen. Faktor yang berkaitan dengan interpersonal adalah religious coping strategis, budaya, tingkah laku, pola asuh serta attachment.

\section{Hubungan Kecemasan Akademik dengan Regulasi Emosi}

Kecemasan akademik mempunyai keterkaitan dengan berbagai faktor.Salah satu faktor yang terkait dengan kecemasan akademik adalah regulasi emosi.Sajadi at al (2012) menyatakan bahwa terdapat hubungan yang signifikan antara kecemasan dan regulasi emosi. Hampir bersamaan dengan pernyataan di atas, Sumida (2010) menyatakan bahwa regulasi emosi dapat mempengaruhi tingkat depresi.

Banyak ahli yang menguatkan bahwa ada keterkaitan kecemasan akademik dengan regulasi emosi.Mennin et al (2009) mengungkapkan bahwa kecemasan mempunyai kontribusi terhadap kesadaran emosi dan penerimaan emosi, yang merupakan indikator dari regulasi emosi. Hampir bersamaan dengan pendapat Mennin et al (Cisler, 2010) menyatakan bahwa kesulitan dalam regulasi emosi akan meningkatkan kecemasan dan penggunaan teknik regulasi emosi akan mengurangi kecemasan. Hal ini juga didukung oleh pendapat Roemer et al (2009) yang menegaskan bahwa kesulitan regulasi emosi berpengaruh terhadap kecemasan.

Berdasarkan beberapa pendapat di atas dapat disimpulkan bahwa kecemasan akademik mempunyai keterkaitan dengan regulasi emosi. Semakin tinggi regulasi emosi siswa maka akan semakin rendah kecemasan akademik dan begitu sebaliknya semakin rendah regulasi emosi siswa maka akan semakin tinggi kecemasan akademiknya. Arinya peningkatan regulasi emosi siswa sangat penting untuk mengurangi kecemasan akademik.

\section{Langkah-langkah Pelatihan Regulasi Emosi Untuk Mengelola Kecemasan Akademik Siswa}

Berdasarkan pendapat dua orang ahli sebagai pencetus teknik regulasi emosi, yaitu Gross \& Thompsom (2007) proses terjadinya regulasi emosi terbagi atas dua, yaitu berfokus pada pemicu regulasi emosi, dan berfokus pada respon regulasi emosi. Adapun pemicu regulasi emosi yang pertama adalah penyeleksian situasi.Maksud dari penyeleksian situasi adalah dimana individu menghindari atau mendekati tempat, orang atau isyarat potensial lainnya untuk dapat mengatur 
respon emosional. Contohnya siswa yang mengalami kecemasan kronis dalam menulis makalah, maka akan memilih jurusan yang tidak terlalu banyak menuntut pembuatan makalah.

Adapun pemicu regulasi yang kedua adalah modifikasi situasi, Modifikasi situasi adalah dimana individu mengubah elemen-elemen dalam situasi untuk menambah atau mengurangi kemampuannya untuk mendapatkan respon emosional yang labih baik.Contohnya ketika terpaksa membuat makalah, siswa yang mempunyai kecemasan kronis memilih topik makalah yang menarik dan sesuai minat.

Pemicu regulasi yang ketiga adalah penyebaran atensional. Maksud dari penyebaran atensional ini adalah memilih untuk fokus pada satu atau aspek lain yang memodulasi dampak situasi emosional. Contohnya siswa yang cemas dalam membuat makalah, tidak mengingat berapa halaman lagi makalah akan selesai, akan tetapi melihat kemajuan yang sudah dicapai dalam pembuatan makalah.

Fokus pemicu regulasi emosi yang terakhir adalah kontrol kognitif, Maksud dari pengontrolan kognitif adalah dimana siswa menempel atau merubah arti khusus dari situasi untuk mengubah dampak emosionalnya. Contohnya siswa merasa cemas mengikuti ujian, dalam situasi ini siswa mengontrol cara berfikirnya dengan menganggap ujian adalah kesempatan untuk naik kelas, bukan kesempatan untuk gagal.

Selain fokus pada pemicu regulasi emosi, Gross and Thompson juga menyatakan proses regulasi emosi yang selanjutnya adalah respon-difokuskan. Maksud dari respon-difokuskan adalah mencoba untuk merubah salah satu kecendrungan respon (pengalaman, fisiologis dan perilaku) yang kurang tepat.Misalnya siswa memfokuskan untuk mengurangi atau menghentikan perilaku cemas ketika ujian. Berikut akan ditampilkan gambar model respon regulasi emosi.

Gambar 1.

Model Respon Regulasi Emosi

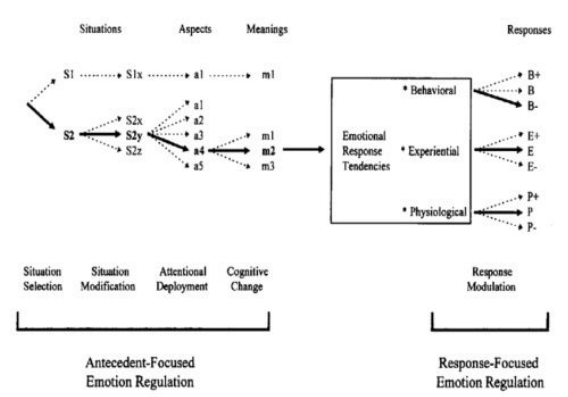

Sumber: Gross and Thompsom (2007)

Berdasarkan

langkah-langkah

regulasi emosi di atas, maka bisa diadopsi untuk pelatihan regulasi emosi, dalam rangka mengurangi kecemasan akademik siswa.Azizi et al (2010) mengungkapkan bahwa pelatihan regulasi emosi efektif untuk mengembangkan kemapuan bertoleransi terhadap distress dan mengurangi kecemasan. Langkah-langkah pelatihan regulasi emosi yang dapat diberikan kepada siswa adalah:

1. Memberi pemahaman kepada siswa tentang pengertian, tujuan dan manfaat regulasi emosi dalam mengurangi kecemasan akademik siswa.

2. Melatih siswa untuk dapat menghindari atau mendekati tempat, orang atau isyarat potensial lainnya untuk dapat mengatur respon emosional. Contohnya siswa disarankan untuk memilih jurusan yang sesuai dengan bakat dan minatnya, dan menghindari jurusan yang tidak sesuai dengan bakat dan minat. Sehingga dapat menghindari kecemasan akademik yang berkepanjangan.

3. Siswa dilatih untuk dapat memodifikasi situasi, dimana siswa mengubah elemen-elemen dalam situasi dengan mengurangi 
atau menambah kemampuannya untuk mendapatkan respon emosional yang lebih baik. Contohnya ketika siswa cemas mendapatkan tugas membuat makalah, maka pilihlah topik makalah yang menarik dan materinya mudah untuk dikuasai.

4. Melatih siswa untuk dapat menerapkan penyebaran atensional, yaitu untuk fokus pada satu aspek atau aspek lain. Hal ini akan memudahkan siswa untuk mengelola dampak emosional dari situasi tertentu dalam belajar. Contohnya siswa tidak mengingat berapa banyak lagi pekerjaan rumah (PR) yang akan dikerjakan, akan tetapi mensyukuri sudah berapa banyak PR yang telah diselesai.

5. Melatih kontrol kognitif siswa. Maksudnya adalah siswa merubah arti khusus dari situasi yang dialami di sekolah, untuk mengubah dampak emosinal dari situasi tersebut. Contohnya, ketika siswa cemas akan menghadapi ujian, maka siswa berfikiran bahwa ujian adalah peluang untuk naik kelas, bukan untuk gagal.

6. Terakhir, siswa dilatihkan untuk mengatur respon, maksudnya merubah salah satu kecendrungan respon yang kurang tepat. Respon tersebut terkait dengan pengalaman negatif, gejala fisiologis negatif, atau perilaku negatif terkait kecemasan akademik. Misalnya siswa memilih untuk fokus pada mengurangi atau menghentikan perilaku cemas ketika ujian. Siswa akan fokus pada pengurangan perilaku tersebut.

Demikianlah langkah-langkah pelatihan regulasi emosi yang dapat dilakukan untuk mengurangi kecemasan akademik siswa.Melalui 6 langkah-langkah tersebut diharapkan kecemasan akademik siswa dapat dikurangi, hal ini diharapkan berdampak pada peningkatan prestasi akademik siswa.

\section{SIMPULAN}

Kecemasan akademik adalah perasaan mental yang berat atau reaksi distress terhadap situasi sekolah karena adanya persepsi negatif, yang dapat dilihat dari cognitive symtoms, emotional symtoms dan bodily symtoms. Jika tingkat kecemasan akademik siswa tinggi, dikhawatirkan prestasi akademik siswa akan rendah. Berdasarkan berbagai data penelitian yang ada, terungkap bahwa tingkat kecemasan akademik siswa Indonesia dominan dalam tingkatan sedang dan tinggi. Jika kondisi ini dibiarkan, kualitas siswa Indonesia akan menturun. Untuk mengatasi permasalahan ini, diperlukan intervensi tertentu, salah satu intervensi yang dapat diberikan adalah pelatihan regulasi emosi. Langkah-langkah pelatihan regulasi emosi tersebut adalah: (1) memberi pemahaman kepada siswa pengertian, tujuan dan manfaat regulasi emosi, (2) melatih siswa menyeleksi situasi, (3) melatih siswa memodifikasi situasi, (4) melatih siswa untuk dapat menerapkan penyebaran atensional, (5) melatih kontrol kognitif siswa, (6) terakhir, siswa dilatihkan untuk mengatur respon.

\section{DAFTAR RUJUKAN}

Al-Qaisy. 2011. The Relation of depression and Anxiety in Academic Achievement Among Group of University Student. International Journal of Psychology and Counseling Vol 3(5) PP 95-100, May.

Azizi et al. 2010.The Effectiveness of Emotional Regulation Training and Cognitive Therapy on the Emotional and Addictional Problem of Substance Abuser.Journal Iranian $J$ Psychiatry5, 2 Spring PP 60-65. 
Baumesiter et al. 2008.Social Psychology and Human Nature. Belmont California: Thomson Wordsworth.

Benoit \& Bouthiller. 2010. Emotion Regulation Strategis As Mediators Of association Between Level of Attacment Security And PTSD Symtomts Following Trauma In Adutlhood. Journal of Anxiety, Stress \& Coping Vol 23, No 1, Januari PP101-118.

Bhansali \& Trivedi. 2008. Academic Anxiety Gender Specific: A comparative Study. Journal Social Science 17 (1) PP 1-3.

Campel, et al. 2006.Test Anxiety and Academic Performace in Undergraduate and Graduate Student.Journal of Educational and Psychology, Vol 97 No 2 PP 268-275.

Campos J.J, Walle, E.A, Dahl, A \& Main, A. 2011. Reconceptualizing Emotion Regulation.Journal emotions Review Vol 3 No 1 (January) PP 26-35.

Cassady, C.J \& Johnson, R.E. 2002. Cognitive Test Anxiety and Academic Performace. Journal of ContemporaryEducational

Psychology 27, 270-295 (2002) pp 270-295.

Cassady, C.J. 2001. The Stability of Undergraduate Student Cognitive Test Anxiety Levels. Journal Practical Assesment, Research and Evaluation, Vol 17, 30 january PP 16.

Cisler,M.J, Olatunji, B.O Feldner M,T \& Forsyth, J.P. 2010. Emotion Regulation and the Anxiety Disorders : An Integrative Review.Journal psychopathological Behavior Assesment, March ; 32(1); PP 68-82.

Corsini. 2009. Examining The Relationship Between Religius Coping Strategis, Attachment Belief And Emotion Regulation In Mixed Sample Of College Student.Dissertation To The
Faculty Of The College Of Arts And Science Liberty University.

Dedeyn, R. 2008. A Comparison of Academic Stress Among Australian and International Student.Journal of Undergraduate Research XI (2008) PP 1-4.

Fransiska, V.A. 2010. Stabilitas dan pengelolan emosi siswa.BK FIP Universitas Pendidikan Indonesia.

Fay. 2011. A Longitudinal Examination of Children' Emotion Regulation Problem, Negative Parenting Behaviors, and the Development of Internalizing Behavior Problems. Dissertation of The University of Michigan.

Frieda, N.H. 1993. Moods, Emotion Episodes and Emotions. New York: Guilford Press.

Garnefski \& Kraaj. 2007. The cognitive emotion regulation questionnaire psychometric features and prospective relationship with depression and anxiety in adult. European Journal Psychological Assasment Vol.23(3) pp 141-149.

Gross \& Thompson. 2007. Emotional Regulation : Conceptual Foundations . USA : Guilford Press.

Izard, C,E, Wooburn, E,M, Finlon,K.J, Ewing, E.S.K, Stacy R. Grossman, S.R \& Adiena Seidenfeld. Journal of Emotion Review Vol.3 No 1 (January 2011) PP 44-52.

Kappas. 2011. Emotional and Emotion Regulation Are One. Journal Emotional Review Vol 3. No 1 January PP 17-25.

Kállay, Tincas, E, Benga, I, \& Oana. 2009. EmotionRegulation, Mood States, and Quality of Mental Life.Journal Cognitie, Creier, Comportament, Vol. 13, No. 1, March 2009 PP 1-10.

Kesek. 2010. Direct and Indirect Approaches to Emotional Regulation in Children. Dissertation of the University of Minnesota 
Lopes.et al. 2005. Emotion Regulation Ability and Social Interactions Quality. Journal The Emotion, 5 (1) PP 113-118.

Lu, Wei Wang, \& Zhenhong. 2012. Emotional Expressivity, Emotion Regulation, and Mood in College Students: A Cross-Ethnic StudySocial Behavior and Personality: an international journal, Vol. 40, No. 2, March PP 1-8.

Marimus. 2012. Emotional Control. Journal APA Des Vol 27 No 12. Washinton, $D C$.

Mato \& Nabi. 2012. Study on Academic Anxiety Among Adolescents. International Journal of Social Science Tomorrow Vol 1. No 1 May. PP 1-3.

Mennin, et al. 2009.Emotion Regulation Deficits in Generalized Anxiety Disorder, Social Anxiety Disorder, and Their Co-occurrence.Journal of Anxiety Disorder Vol 23. PP 866-871.

Moorman, D. 2011. Emotional control.Journal of FredicEm. Vol. V. P 25

Oxford dictionaries

http://oxforddictionaries.com/definiti on/english/emotion.posted dec, 20 2002.

Owen at al. 2012. Anxiety and Depression in Academic Performance: An Exploration ot the Mediating Factor or Worry and Working Memory. Journal of School Psychology International, 7 February PP 1-17.

Roemer et al. 2009. Mindfulness and Emotion Regulation Difficulties in Generalize Anxiety Disorder: Preliminary Evidence for Independent and Overlapping Contributions. Journal of Behavioral Therapy, 40 PP 142-154.

Safitri, E. 2011.Gambaran Kecemasan Akademik Siswa Di SMA N Unggul Aceh Timur. USU Intitutional Respository.
Sajadi, S, et al. 2012. The Relationship between anxiety and emotion regulation with psychological hardiness in student.Journal of Annals of Biogical Research, 3 (10) pp 4964-4969.

Sumida.2010. Clarifying the Relationship Between Emotional Regulation, Gender, and Depression. Dissertation in Psychology, Utah State University.

Tamir, M. 2011. The Maturing of Emotion Regulation.Journal of Emotio Review Vol 3. No.1 (January) PP 3-7

Thompson. 1994. Emotional Regulation. A Theme In Search of Definition. Monographs of The Society for Research in Child Development, Vol $5 \mathrm{NO} 2 / 3$.

Santrock, J.W. 2007.Educational Psychologi. Canada: McGraw-Hill Ryerson Press.

Schmidt, et al. 2010. Appraisals, Emotion and Emotion Regulation: an Intergrative Approach. Journal Motivation Emotion, March, 34 (1) PP 63-72.

Smith, P \& Renk. 2007. Predictors of Academic- Related Stress in College Student: An examination of Coping, Social Support, Parenting and Anxiety. NASPA Journal, Vol 44 No 3 PP 405-429.

Stifter, C.A. 2002. Individual Differences in Emotion Regulation in Infancy: A Thematic Collection. Journal INFANCY, 3 (2), PP 129-132, Lawrence Eribaum associates, inc.

Vitasari, Wahab, P, Othman, M.N.A, Awang, A, \&Ghani, M. 2010.The Use of Study Anxiety Intervention in Reducing Anxiety to Improve Academic Performance among University Students.International Journal of Psychological Studies vol 2, no 1 june pp 1-6.

Wahyuni, E.N. 2005.Pengembangan Paket Pelatihan Pengendalian Emosi 
Untuk Siswa SMP. Tesis.Pascasarjana Jurusan BK UM. Yasin, M.A.S.N \& Mariam Adawiah Dzulkifli, M.A. 2009. Differences in Problem Between Low and High Achieving Student.The Journal of Behavioral Science, Vol 4, No 1, PP 49-58.

Y.C Singh. 2009. Level of AcademicAnxiety : Self Confidence and Their Relation with Academic Achievement in Secondary Student. International Research Journal, 2009 Vol 1 Issue 7 PP 12-13.

Yousefi. 2009. Memory in Mediator Between Test Anxiety and Academic Achievement in High School Student. European Journal of Scientific Research. Vol 35 No 2 PP 274-280. 